\title{
Study on the Current Situation and Problems of Intelligent Community Construction in Chengdu
}

\author{
Minghong Tang* \\ Southwest Jiaotong University, School of Public Affairs \& Law, China Chengdu 610031 \\ *Corresponding author. Email: 826502083@qq.com
}

\begin{abstract}
Along with the development of economy and society, the concept of intelligent city and intelligent community emerged and was introduced to China with the development of emerging technologies such as Internet of Things and big data. Since it was approved as one of the first pilot demonstration cities of intelligent cities in China in 2013, Chengdu has been actively exploring the construction of intelligent community. After the development in recent years, the construction results are remarkable, and some community pilot projects have been successfully accepted. However, it still seems to be in the primary stage, and there are gaps and shortcomings compared with developed regions. Based on the field research of some intelligent community in Chengdu, we analyze the current situation of intelligent community construction in Chengdu, and propose countermeasures and suggestions from the common problems reflected by several representative community to promote the better construction and development of intelligent community and intelligent cities in Chengdu.
\end{abstract}

Keywords: Intelligent community, Community construction, Chengdu.

\section{INTRODUCTION}

The construction of intelligent cities is a long and systematic process, as well as a process of continuous exploration. The construction of intelligent community in Chengdu began in 2013, when Chengdu became one of the first pilot demonstration cities of intelligent cities in China [1]. In May 2016, Chengdu conducted a pilot intelligent community in HongGuang Community, LiuCheng Street Office, WenJiang District, and RuiQuan XinCheng Community, YongQuan Street Office, and eventually these two community completed the initial intelligent construction. To further standardize the construction of intelligent community, a white paper on the standardization of intelligent cities in Chengdu was released in November 2019. To further understand the current construction status of intelligent community, the author launched a field research on some intelligent communities in Chengdu.

\section{THE CURRENT SITUATION OF INTELLIGENT COMMUNITY CONSTRUCTION IN CHENGDU}

According to the research results, the following will mainly introduce the current situation of intelligent community construction in Chengdu from four aspects: intelligent management, intelligent property, intelligent home and intelligent service.

\subsection{Community Intelligent Management Current Status}

Community intelligent management uses various resources to provide a comfortable and convenient living environment for residents through information and communication technologies such as the Internet of Things, the Internet, and big data. The research data show that the community's conflict and dispute mediation service network platform is working well. However, the data also show that nearly $40 \%$ of the residents do not enjoy the services of the dispute mediation platform, which shows that the platform needs to be further improved in the process of intelligent community construction. In addition, community security management is also an important component of community intelligent management. The comprehensive survey data shows that the current security management of Chengdu's intelligent community can basically meet the demand, but there is still a gap from full coverage. 


\subsection{Community Intelligent Property Current Status}

Community property services are mainly for the daily management and maintenance of houses, community environment, and supporting facilities, as well as providing various value-added services, such as. vehicle management, access control, etc. [2]. However, many old community in Chengdu have poor infrastructure conditions, so it is difficult to enjoy the same intelligent as new community in the process of intelligent community construction. In addition, the property has carried out preliminary intelligent construction in disaster alarm and accident prevention, using advanced technology to reduce security risks, but there is still a gap to build a intelligent community with full coverage of security management services and more complete equipment. The study also found that the main way for residents to pay their bills using information technology is through online software terminals, and that Chengdu has joined hands with several government departments and enterprises to launch a one-stop service platform "Tianfu Citizen Cloud" to facilitate residents' lives.

\subsection{Community Intelligent Home Current Status}

The intelligence of residents' homes is the use of various information and communication technologies and control systems to integrate home facilities to improve the quality of life of residents within the scope of their homes [3]. The survey found that it is difficult to achieve integrated intelligent management because intelligent homes, especially fully functional and comprehensive systems, are often complex to install and use, have high prices and varying product quality, and have poor compatibility between different brands. The data also shows that residents prefer subsystems that can enhance the physical environment, especially intelligent home appliance control and intelligent security control, while the preference for systems that enhance the quality of residents' spiritual life is low. Security monitoring is one of the important subsystems of intelligent home, but in general, compared with security monitoring subsystem, appliance control subsystem is more favored by residents.

\subsection{Community Intelligent Services Current Status}

Intelligent services refer to the promotion of community development through the informationization of equipment, products, and services, and the provision of intelligent services covering public services, living services, and commercial services to residents [4]. The results of the research show that in the government service, the highest realization rate of the intelligent community in Chengdu uses information technology means to provide e-government online services; in the elderly service, the realization rate of the intelligent community in Chengdu uses information technology means to carry out elderly services is low; in the cultural service, the survey found that the realization rate of borrowing books from the community library through information technology means is also relatively low; in the help service, the community The survey shows that the realization rate of setting up special community service channels for disadvantaged groups through information technology means is low.

\section{THE PROBLEMS OF THE CONSTRUCTION OF INTELLIGENT COMMUNITY IN CHENGDU}

Although the construction of intelligent community in Chengdu has achieved remarkable results in recent years, the degree of construction is still not perfect, whether in terms of policy system, infrastructure or practical application, and some problems and shortcomings are worth further consideration and discussion.

\subsection{Lack of Integrated Planning}

Chengdu has not yet launched the construction guidelines for intelligent community, which makes each body lack of unified planning and clear objectives, in the process of participating in the construction of community intelligent in their own way, it is difficult to form a synergy and promote as a whole. In terms of the government, the relevant departments have not yet issued construction guidelines, work programs or planning, and the goal of community intelligent construction is unclear; inter-departmental barriers have not been broken, horizontal collaboration is difficult, and it is difficult to truly build a unified information management platform when intelligent government is sunk into the community; in terms of the community, in practice in Chengdu, due to the lack of integrated planning, each community to try on their own, resulting in duplication of development, independent operation, and waste of resources. In practice, in Chengdu, due to the lack of integrated planning, each community tries to do it on its own, resulting in duplicate development, independent operation and waste of resources.

\subsection{Insufficient Financial Security}

The source of funds for the community is mainly the government's financial allocation, and this part of the allocation can only be "earmarked". However, it is difficult to meet the long-term development needs of the community intelligent construction by relying only on the government's financial allocation, and the government occupies the position of the only main body 
of the intelligent community construction and operation, which to a certain extent also limits its diversified development. In the practice of intelligent community construction in Chengdu, there are some enterprises have made investments and tried to build and operate. However, due to the complex content and high cost of intelligent community construction, enterprises as the main body of capital investment, the initial profitability difficulties, the development of maturity requires a long time cycle, the enthusiasm of enterprises also declined. This makes it difficult to maintain the practice of intelligent community construction in Chengdu with enterprises as the main investment body after one or two years.

\subsection{Lack of Professional Talents}

First, there is a shortage of community staff. Due to the many tasks of community grassroots work, community staff at the end of the need to do everything personally, and each community is equipped with a limited number of staff. Different departments in the intelligent construction of the creation of intelligent information platform is often fragmented, sinking to the grassroots community when the staff in the intelligent construction of the task is not reduced but increased, intelligent equipment does not really let the community work to reduce the burden. Second, the community staff professionalism in general. Community staffs poor grasp of the core technology of the community intelligent system is also one of the factors limiting the development of intelligent community, the current intelligent of the social work team is lagging behind, the relevant services and technical personnel is still relatively scarce. And the existing intelligent community-related training and education is less developed, in the context of the rapid development of information technology, the professional shortage of community staff further increases.

\subsection{Digital Divide}

The development of community is already unbalanced, the level of infrastructure construction, the degree of technical mastery varies, and the intelligent of each community system is difficult to achieve interoperability, resulting in fragmented and low integration of community intelligent construction, there is a "digital divide" between different community. For example, in old courtyards, self-built houses, demolition and resettlement community and other more concentrated community, because of the lower level of intelligence, residents enjoy the limited effectiveness of the intelligent of the construction. In addition, the construction of intelligent community requires community staff and residents to have the correct awareness of intelligent construction and the ability to successfully use intelligent applications, but field research reflects the lack of awareness and ability to use information technology among the elderly, and the existence of a "digital divide" between the elderly and young people, to promote intelligent applications to them There are often difficulties in promoting intelligent applications to them.

\section{SUGGESTIONS FOR THE INTELLIGENT COMMUNITY CONSTRUCTION IN CHENGDU}

Intelligent community construction in Chengdu needs to recognize the current problems faced and take corresponding measures in order to give full play to the effectiveness of intelligent construction and further achieve results.

\subsection{Strengthen the Top-Level Design}

The top-level design can be optimized through four aspects: clear direction of collaborative construction, standardization of standards, differential piloting to avoid duplication, and integration starting from the government [5]. Specifically: (1) the direction of collaborative construction should be clarified. Combined with the economic anda technological level of Chengdu and local people's conditions, Chengdu should clarify the idea, concept and goal of intelligent community construction; (2) standardization criteria. The Chengdu government can study practical construction and evaluation standards according to the existing construction situation of each community, so as to provide reference for community construction and standardize and unify the construction content; (3) Differential pilot to avoid duplication. After the government has developed the corresponding standards, should use the pilot first work method, to be combined with the different circumstances of each community, planned regulation, respectively, pilot, so that different community for differentiated construction; (4) unified integration. The scope of intelligent community is large and involves many fields and departments, so the Chengdu government can set up relevant departments or groups to make unified deployment of intelligent community construction in Chengdu.

\subsection{Ensure the Intelligent of the Community Construction Funds}

Intelligent community construction can not be separated from the government's financial support, intelligent community construction in all aspects of capital investment is large, so the Chengdu municipal government in the financial can be properly tilted to ensure that the community intelligent construction can operate normally. At the same time can also provide policy preferences and institutional safeguards to introduce diversified social investment, to make up for 
insufficient funds to ensure sustainable development, and constantly improve the level of construction.

\subsection{Cultivating Talents for Intelligent Community}

By using the resources of the academic community, cultivating intelligent social workers, cultivating intelligent residents, and cultivating intelligent humanities to create a talent team for intelligent community construction. (1) To make use of academic resources, the government can encourage colleges and universities and relevant scientific research institutions to actively engage in research on intelligent community, bring into play the power of scientific research and innovation, transform their academic achievements into the ground, and guide the practice of intelligent community; (2) to cultivate intelligent social workers. The Chengdu government should create an environment conducive to the development of relevant talents through preferential policies and resource advantages to attract more talents to invest in the construction of intelligent community, pay attention to talent needs to retain talents, and promote the development of community staff teams in the direction of professionalism and youthfulness; (3) to cultivate intelligent residents. The community can guide residents to correctly understand the functions of the intelligent community through public propaganda, practical experience, and encouraging learning, help residents to use intelligent applications, let residents feel the convenience and comfort brought by the intelligent construction, and strengthen residents' sense of identity to adapt to the intelligent community construction; (4) to cultivate intelligent humanities. By building volunteer services, interest groups and communication platforms, we can help residents expand the space for interaction with their neighbors and cultivate their sense of community by combining online and offline; we should also encourage residents to actively participate in community intelligent construction for self-service and self-management.

\section{CONCLUSION}

Overall, the construction of intelligent communities in Chengdu is still in its infancy, with some shortcomings, but also advantages. This paper introduces and analyses the current situation of intelligent community construction in Chengdu, further analyses the problems of intelligent community construction in Chengdu, and puts forward suggestions for various aspects. It is hoped that in the future, with the joint efforts of the government, enterprises, society and citizens, Chengdu's communities can become even smarter.

\section{AUTHORS’ CONTRIBUTIONS}

In general, the construction of intelligent community in Chengdu is still in the primary stage, and although many community have actively explored and achieved remarkable results, there are still some realistic problems and shortcomings. Based on such a realistic situation, this study analyzes the current situation and problems of intelligent community construction in Chengdu through literature review and field survey. First, it introduces the situation of intelligent community construction in Chengdu in recent years from four aspects: intelligent management, intelligent property, intelligent home, and intelligent service, further analyzes the problems of intelligent community construction in Chengdu, and puts forward suggestions for strengthening top-level design, securing funds, and cultivating talents. There is still much to be researched and explored in order to give full play to the economic and social benefits brought by the development of intelligent community in Chengdu, which requires not only the efforts of the government, enterprises and academia, but also the active participation of residents, in order to finally realize the common construction, governance and sharing of intelligent community.

\section{ACKNOWLEDGMENTS}

I would like to express my gratitude to the scholars cited in this thesis; your wisdom and efforts have been of great help to me. I would like to thank Associate Professor Liu, whose guidance and suggestions have improved this thesis.

\section{REFERENCES}

[1] Xiao Yu. Study on the development practice of intelligent community in China and its prospect [D]. Shanghai Academy of Social Sciences,2016.

[2] Wu Zhengfeng, Wang Feng. Innovative development ideas of property management based on the construction of intelligent community[J]. Journal of Anhui University of Technology: social science edition,2016,33(1):17-18.

[3] Ma Xiaopeng. Intelligent home, intelligent life [J]. TV Technology,2014,0(S1):54-58.

[4] Zhang Dapeng, Wang Yi. Research on the evaluation index system of intelligent community (park) construction[J]. Engineering construction standardization,2015,0(2):71-73.

[5] Li Guoqing, Li Yi. The dilemma and the way out of China's intelligent community construction[J]. Journal of Guangzhou University: social science edition,2015, 14(12):67-71. 